\title{
XXVIII Festival Internacional de Teatro Hispano de Miami
}

\section{Luis F. González-Cruz}

Nunca antes tuvo este Festival — del 11 al 28 de julio de 2013, dirigido por Mario Ernesto Sánchez- la magnitud de su vigésima octava edición. Con cuatro salas disponibles, se aumentó el número de piezas escenificadas. El 20 de junio se develaron los afiches del Festival y del Día Internacional del Niño, diseñados por la artista peruana Carmen Sasieta, como parte del homenaje que se le hizo a Perú. La velada contó con el monólogo La madre (escrito por Sara Joffré González, dirigido por Jacqueline Briceño y montado por Teatro Avante, Miami), magistralmente interpretado por Danly Arango en el papel de una mujer que se hace pasar por transformista, apareciendo en un espectáculo denigrante, el cual está a punto de descubrir y presenciar su hijo. El peruano Ernesto Ráez Mendiola fue el recipiente del Premio a Una Vida de Dedicación a las Artes Escénicas. Hubo tres exhibiciones: de fotos de Asela Torres de obras peruanas incluidas en anteriores Festivales; de pinturas del artista peruano José Torres Böhl; y de vestuario y escenografía diseñados por Nobarte (Jorge Noa y Pedro Balmaseda). El Componente Educativo, organizado por la Dra. Beatriz Rizk, incluyó conferencias, foros después de las funciones, cine y presentación de libros, entre ellos un volumen que comenta los primeros veinticinco años del Festival. Hubo también un concierto de música barroca, Las fuentes de Bimini ("La Folía", Madrid, España; director: Pedro Bonet) - para celebrar el 500 aniversario de la llegada de los españoles a la Florida - dedicado a composiciones relacionadas con el descubrimiento, exploración y colonización de las Américas (siglos XV-XVIII); y otro de jazz (Coming Home; "Jaume Vilaseca Trío", Barcelona, España).

Los ríos profundos (escrito por José María Arguedas, dirigido por Mario Delgado Vásquez y montado por Cuatrotablas, Lima) fue una dramatización de la novela de Arguedas, cuyo protagonista es un niño mestizo, criado entre indios y educado en el ambiente triste de un colegio religioso, 
desde el cual se lanza a la búsqueda de su progenitor, enfrentándose a las singularidades (buenas y malas) de su pueblo. Dos eficaces actrices, vestidas a la usanza indígena del Perú, relatan, de manera recitativa, eventos de la novela con la asistencia de un actor que lee el texto. Cyrano mío (escrito por Iliana Prieto y Cristina Rebull, dirigido por Joann Yarrow y Cristina Rebull y montado por Teatro Prometeo, Miami) sobresalió en todo. En esta adaptación de Cyrano de Bergerac, la actuación mesurada, sentida, justa, de Claudia Quesada en el papel de Roxana, quedará en la memoria de los asistentes. Igualmente convincente fueron las de Luis Martínez (Cyrano) y Luis Fuentes (Christian de Neuvillette). Lisset Riera, Diego Moreno y Luis Fuentes interpretaron hábilmente varios personajes. El vestuario y la escenografía de Nobarte estuvieron a la altura de la lúcida dirección, el diseño de luces y la música. En El país de las maravillas (escrita y dirigida por Omar Varela y montada por Nidia Telles-Alejandro Martínez Co., Montevideo) Alejandro Martínez es "El hijo" que vuelve de Nueva York a Montevideo con la intención de quedarse en su país; Nidia Telles es "La madre", quien esperaba viajar con él cuando regresara a los Estados Unidos, pero se ve obligada a irse sola, con visa turística, para tratar de quedarse allí ilegalmente y mejorar sus condiciones de vida. Las autoridades de inmigración en Miami la devuelven a Uruguay al confesar ella ingenuamente cuáles son sus planes. La comedia - comercial - hace comentarios sobre los problemas de inmigración y otros males sociales de los dos países con el mero propósito de entretener y hacer reír, lo cual logra ampliamente. La paz perpetua (escrita por Juan Mayorga, dirigida por Olga Margallo y montada por la Compañía Nacional de Teatro de México, DF), mise en scène de primer orden, debe su título al tratado de Kant Sobre la paz perpetua (1795), que concebía posible construir un orden jurídico que lograra abolir las guerras. Tres actores hacen de perros adiestrados, encerrados en un centro especial de entrenamiento que los capacitará como sabuesos dedicados a combatir el terrorismo. Se producen rivalidades entre ellos con el propósito de ser "el primero" en la selección final que escogerá a uno como ganador de la plaza que conlleva la investidura del "collar blanco" símbolo de paz. El proceso que conduce a la elección lo realizan otros dos personajes: uno, viejo perro al servicio de la causa que se defiende, y el otro, ser humano representante del "Amo". Se reelaboran asuntos tratados por Pascal y Kant, pero desenfadadamente, con tal agudeza y sentido del humor que hacen reír. La sentencia "para salvar la ley a veces es necesario transgredirla" define el mensaje de la obra: los medios (aunque cuestionables) justifican el fin, si éste beneficia a la mayoría. Entre 
Nós (escrita y dirigida por João Sanches y montada por Tribo-Companhia de Artes Cênicas, Salvador de Bahia). Dos actores ensayan, discutiendo y escenificando el texto, una pieza sobre un joven virgen que acaba de descubrir su homosexualidad y se enamora de otro, en la misma escuela, que es gay. Porque éste tiene novio, no le presta atención al primero y se pospone el enlace de ambos hasta que el beso definitivo selle oficialmente su relación. Esto ocurre al final, cuando el comprometido se libera del novio y los actores preguntan al público cómo debe terminar la obra, si con un beso, o cantando ambos una canción. Por decisión de la audiencia, se dan el gran beso apasionado, baboso, prolongado - al extremo de que tras producirse el apagón e iluminarse la sala todavía no se han separado-, que nunca sabemos si es de los actores o de los personajes que interpretan. La pieza, simpatiquísima, animada, estupendamente movida, con magníficas actuaciones de Igor Epifanio y Anderson Dy Souza, trata las cuestiones de la diversidad sexual, la homofobia, la tolerancia y los conflictos del amor no correspondido. Salmo 91 (escrito por Dib Carneiro Neto, dirigido por Djalma Thürler y montado por Ateliê Voador Companhia de Teatro, Salvador de Bahia) se basa en el libro Estação Carandiru, de Drauzio Varella, para hacer un recuento de la "masacre de Carandiru", cuando la policía militar disparó a los reos amotinados, a los que se rendían y aun a aquellos que huían despavoridos a refugiarse en sus celdas. Cinco consumados actores realizan una multitud de papeles contando sus historias o expresando sus deseos, que con frecuencia caen en el reino de la sexualidad, un asunto conflictivo entre presidiarios. El Día Internacional del Niño - 21 de julio - se presentó Güepajé (escrito y dirigido por Ciro Gómez Acevedo y montado por la Asociación Cultural Hilos Mágicos, Bogotá), una excelente obra infantil con títeres que trata del hechizo que genera la música y cuyo tema central es la búsqueda de la simbólica y legendaria "Flor del Agua".

Al pie del Támesis (escrito por Mario Vargas Llosa, dirigido por Mario Ernesto Sánchez y montado por Teatro Avante, Miami). La ovación de pie al final de la representación se debió a los aciertos de dirección, luces (Sánchez), música (Mike Porcel), actuación (Marilyn Romero y Julio Rodríguez), la excelente escenografía (Nobarte) y el profesionalismo de esta producción. Chispas, cincuentón, recibe en su hotel de Londres, adonde ha ido en viaje de negocios, la visita de la supuesta hermana de Pirulo, un camarada de juventud que intentó besarlo y recibió a cambio de su acción un bofetón y el golpe de una pesa que el otro le lanzó, horrorizado por la agresión amorosa de su mejor amigo. Han transcurrido varias décadas desde aquel incidente. 
Ahora, la hermana es el propio Pirulo que se ha sometido a una cirugía de reasignación de sexo. El diálogo, de reminiscencias y suposiciones, va por vericuetos inesperados, inexplicables; como mujer, Pirulo/Raquel también ha sido, en el pasado, amante de Chispas. Al final se va Raquel y entra Pirulo, como hombre, para acompañar a Chispas en su cita de negocios. Nunca sabemos qué sortilegio guía al personaje masculino a imaginar tales incongruencias; el espectador deberá interpretar la historia como guste. Quedan claros los comentarios sobre la homofobia, las ambivalencias sexuales o afectivas, y las anécdotas que componen la trama. Marica (escrita y dirigida por Pepe Cibrián Campoy y montada por El Vasco Producciones, Buenos Aires) sobresalió por la fuerza del texto y la talentosa actuación de Cibrián, quien se multiplica para interpretar a García Lorca, su asesino, sus padres, una mujer y Salvador Dalí. Largos pasajes en verso rimado de Cibrián nada tienen que envidiar a los compuestos por García Lorca. Los temas principales tienen que ver con la muerte (o asesinato) del poeta granadino, el hecho de ser diferente y los detalles - documentados o imaginados - de su vida sexual y amorosa. Según Cibrián, de 65 años, abiertamente homosexual, la obra "funcionó como un disparador para apoyar el tratamiento y la sanción posterior de la ley de matrimonio igualitario de la República Argentina". Cinco actores/músicos/juglares — “cómicos de la legua"— animan Siglo de oro, siglo de ahora (escrito por Álvaro Tato, dirigido por Yayo Cáceres y montado por Ron Lalá Teatro, Madrid), un espectáculo divertido, dinámico, con canciones y entremeses que enlazan la España del Siglo de Oro con la actual, trazando paralelismos y diferencias, criticando los males pasados y presentes del país ibérico, pero señalando también sus virtudes. Por allí pasan, entre otros, Cervantes, Shakespeare, Lope, políticos de ayer y de hoy, la Inquisición, la Inmigración, Don Dinero, la Guerra, la Justicia, El Sexo, y hasta Madona, ridiculizada en una canción de esta sostenida chanza: "Jubílate Madona / que estás vieja y culona". Con tal fiesta de sano humor concluyó este variado Festival. [Los conflictos de programación impidieron que presenciara Juan Cristóbal, casi al llegar a Zapadores (escrito y dirigido por Ítalo Gallardo Betancourt y montado por Compañía de Teatro de Laura Palmer, Santiago de Chile) y La madre Pasota y cosas nuestras de nosotros mismos (escrita por Juan Mayorga, dirigida por Mariana Jiménez y montada por UROC Teatro, Madrid)]. 